\title{
Global Use of Idarucizumab in Clinical Practice: Outcomes of the RE-VECTO Surveillance Program
}

\author{
John Fanikos ${ }^{1}$ Debra Murwin ${ }^{2}$ Fredrik Gruenenfelder ${ }^{3}$ Igor Tartakovsky ${ }^{3}$ Lionel Riou França ${ }^{3}$ \\ Paul A. Reilly ${ }^{2}$ Pawel Kermer ${ }^{4,5}$ Fredrik von Wowern ${ }^{6}$ Deirdre A. Lane ${ }^{7}$ Ken Butcher ${ }^{8,9}$
}

\footnotetext{
${ }^{1}$ Brigham and Women's Hospital, Boston, Massachusetts, United States

2 Boehringer Ingelheim Pharmaceuticals, Ridgefield, Connecticut, United States

3 Boehringer Ingelheim International GmbH, Ingelheim, Germany

${ }^{4}$ Department of Neurology, Nordwest-Krankenhaus Sanderbusch, Sande, Germany

${ }^{5}$ University Medical Center Göttingen, Göttingen, Germany

6 University Hospitals of Skåne - Malmö, Skåne, Sweden

${ }^{7}$ Liverpool Centre for Cardiovascular Science, Liverpool Heart and Chest Hospital, University of Liverpool, Liverpool, United Kingdom

8 Prince of Wales Clinical School, University of New South Wales, Sydney, Australia

${ }^{9}$ Department of Medicine, University of Alberta, Edmonton, Alberta, Canada
}

Thromb Haemost 2020;120:27-35.

\author{
Address for correspondence John Fanikos, RPh, MBA, Brigham and \\ Women's Hospital, 75 Francis Street, Boston, MA 02115, United \\ States (e-mail: jfanikos@bwh.harvard.edu; jfanikos@partners.org).
}

\begin{abstract}
Keywords

- anticoagulation

- idarucizumab

- dabigatran etexilate

- real-world utilization

- reversal agent

Idarucizumab was approved for the reversal of dabigatran in 2015. We investigated whether postapproval usage patterns of idarucizumab in a real-world setting reflect those observed in the pivotal trials. No safety or efficacy data were collected in this medical record-based observational study. RE-VECTO, a global postapproval, international, surveillance program, involved hospital pharmacies in countries where idarucizumab was licensed and dispensed (August 2016-June 2018). Characteristics of sites prescribing idarucizumab and of eligible patients ( $\geq 18$ years old and receiving idarucizumab regardless of prior oral anticoagulant use), as well as idarucizumab utilization data, were collected and analyzed descriptively. Sixty-one sites enrolled 359 patients. Most pharmacies $(85.2 \%)$ were centralized, and the median idarucizumab units stocked per hospital was 2.0 (interquartile range, 1.0-3.0). Almost three-quarters of patients were elderly ( $74.9 \%$ aged $>70$ years), and only four $(1.1 \%)$ had received idarucizumab before. Nearly all patients were treated with dabigatran (97.5\%). There was a low frequency of unapproved dabigatran dosage regimens (3.3\%). Life-threatening or uncontrolled bleeding was the most frequent indication for idarucizumab (57.7\%), followed by emergency surgery/urgent procedure (35.9\%). Of the life-threatening bleeding events, the most frequent were gastrointestinal tract (44.4\%) and intracranial (38.6\%). Most patients $(95.0 \%)$ were given the full dose of two vials $(2 \times 2.5 \mathrm{~g})$ of idarucizumab initially, and very few $(1.7 \%)$ received a second dose. Of those patients requiring emergency or scheduled/planned surgery/procedures, $25.5 \%$ underwent gastrointestinal and/or abdominal surgery/procedures. Real-world usage patterns of idarucizumab provide valuable insights into emergency reversal strategies. Off-label use was minimal.
\end{abstract}

received

March 28, 2019

accepted after revision July 19, 2019
DOI https://doi.org/

$10.1055 / \mathrm{s}-0039-1695771$ ISSN 0340-6245.
(C) 2020 Georg Thieme Verlag KG Stuttgart . New York
License terms

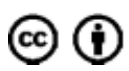




\section{Introduction}

Anticoagulant reversal is central to the management of uncontrolled bleeding in anticoagulated patients and, where possible, in those on anticoagulants who require emergency surgery or other invasive procedures. ${ }^{1}$ The strategy undertaken to attempt reversal will vary according to the type of anticoagulant in use and availability of reversal agents. Nonvitamin K antagonist oral anticoagulants (NOACs), including the direct thrombin inhibitor dabigatran and the factor Xa (FXa) antagonists (rivaroxaban, apixaban, edoxaban, and betrixaban), are now recommended in guideline statements as the preferred agents in most clinical settings due to their similar efficacy and lower bleeding risk compared with vitamin $\mathrm{K}$ antagonists. ${ }^{2-4}$ Reversal of NOACs was not possible until 2015, when idarucizumab became commercially available in the United States and European Union (EU) for the specific reversal of dabigatran., Andexanet alfa was approved in 2018 in the United States for the treatment of rivaroxaban- and apixaban-associated bleeding in patients, but is not yet available elsewhere, nor is it approved for use in surgical patients. ${ }^{7}$ Prior to this, treatment was limited to nonspecific empiric approaches (e.g., administration of blood or blood derivatives, or waiting until anticoagulant activity had waned). Nonspecific approaches are still used in countries that have no approved specific reversal agents, and in bleeding associated with oral anticoagulants (OACs) for which there are no specific reversal agents available.

Idarucizumab is a humanized mouse monoclonal antibody fragment that binds directly to dabigatran with high affinity, reversing its anticoagulant effects within minutes. ${ }^{8,9}$ In the phase III RE-VERSE AD (NCT02104947) trial, idarucizumab rapidly and completely reversed dabigatran's anticoagulant effect in almost all patients with life-threatening or uncontrolled bleeding or those requiring emergency surgery or procedures. In addition, no safety concerns, specifically anaphylaxis or prothrombotic effects, were reported. ${ }^{10}$ Dabigatran is indicated to reduce the risk of stroke and systemic embolism in nonvalvular atrial fibrillation, to treat deep venous thrombosis (DVT) and pulmonary embolism (PE), to prevent recurrent DVT and PE in adults (DVT/PE), and for primary prevention of venous thromboembolism in orthopedic surgery. ${ }^{11,12}$ Idarucizumab ( $5 \mathrm{~g}$ initially; two $50 \mathrm{~mL}$ vials each containing $2.5 \mathrm{~g}$ idarucizumab constitute one complete $5 \mathrm{~g}$ dose [a second $5 \mathrm{~g}$ dose may be considered under specific clinical circumstances]) is indicated in adult patients when rapid reversal of dabigatran is required for life-threatening or uncontrolled bleeding or emergency surgery/urgent procedures. ${ }^{5,6}$

To characterize the utilization of idarucizumab and provide data on usage patterns in a real-world setting, REVECTO, a global drug administration surveillance program, was initiated.

\section{Methods and Analysis}

\section{Program Design and Participants}

RE-VECTO, an international, multicenter, cross-sectional surveillance program, was a postapproval study commitment for the European regulatory authorities. RE-VECTO involved hospital pharmacies or departments in North America, the EU, and the Asia-Pacific region, where idarucizumab was dispensed between August 2016 and June 2018, depending on marketing authorization, country regulations and requirements, and availability of the protocol.

In countries where idarucizumab was approved, potential sites where idarucizumab was dispensed were identified and invited to register; after which data were collected via a retrospective chart review. Initially, all centers who ordered idarucizumab were sent a welcome pack and invited to register on the Web site. The response rate was low and the process was redefined to include only those centers that ordered and then restocked idarucizumab. However, this was not necessarily indicative of use of idarucizumab as reorders could be for multiple reasons (i.e., supplying satellite locations within the hospital or toward the end of the trial-replacing expired product). In total, over 2,000 invitations were sent, and other methods were used to narrow site selection to those with known patients receiving the product (i.e., claims data or medical science liaison conversations). All centers that registered, completed required training, and finalized the required trial documents were activated, regardless if they had an identified patient or not.

Idarucizumab was prescribed at the discretion of the treating physician and not influenced by participation in the program. Prescription of idarucizumab other than indicated by the label was considered as off-label use, such as an unapproved indication (e.g., elective surgery), an unapproved dose (e.g., $2.5 \mathrm{~g}$ ), or treatment of a patient who did not receive dabigatran. Patients aged $\geq 18$ years receiving idarucizumab as part of their clinical care were eligible, regardless of prior OAC use. Any patients participating in a dabigatran or idarucizumab clinical trial were excluded.

Informed consent was not required because the program was based on anonymized data. The protocol was approved by an independent ethics committee where necessary, based on country-specific regulations.

\section{Data Collection}

In patients treated with idarucizumab, anonymized patient data were entered into an electronic data capture system via an Internet portal. A prespecified data-management plan and prespecified rules generated autoqueries for missing fields, and data listing reviews were conducted prior to database lock. Patient demographics such as age categories and previous anticoagulant use (e.g., last intake of dabigatran etexilate or other OACs) were collected. Previous antiplatelet treatment, safety, and efficacy data were not collected.

Idarucizumab utilization, including the reason for idarucizumab use (life-threatening or uncontrolled bleeding requiring medical intervention, or emergency surgery or other urgent medical procedure necessitating rapid reversal of the anticoagulant effect of dabigatran), was recorded. Information regarding the location of the bleeding event (gastrointestinal [GI] tract, intracranial, postprocedural, skin, urogenital tract, undefined location, other defined location) was also collected. In addition, the dosage and timing of idarucizumab administration (total dose administered and the time interval between 
administration of the first and second vials [the standard approved dosage is $2 \times 2.5 \mathrm{~g}$ vials]), whether idarucizumab administration was discontinued prematurely, and the care setting (e.g., emergency department, intensive care unit, or operating room) were recorded.

The characteristics of the hospital pharmacy were collected for each participating site to evaluate the diversity of sites, including: country, whether the pharmacy was central or decentralized, the number of pharmacy units within the hospital if there is no central pharmacy (e.g., the emergency department, intensive care unit, or operating room), idarucizumab stocks, storage location, distribution channels within the hospital, type of practice (academic, nonacademic, private, or public), and availability of electronic prescription records at the pharmacy.

\section{Statistical Analysis}

The program sample size was driven by regulatory requirements, and idarucizumab usage and provider participation. A minimum of 300 patients was requested by the European Medicines Agency.

Data from all enrolled patients who received idarucizumab were analyzed using descriptive statistics (generated using SAS version 9.2 or higher [SAS Institute, Cary, North Carolina, United States]). Categorical variables were summarized as numbers and proportions. Continuous variables are reported as mean (standard deviation [SD]) or median (interquartile ranges [IQRs]). Subgroups analyzed included region, indication for use of idarucizumab, age, prior administration of idarucizumab, department where idarucizumab was administered, bleeding event location and type, and whether the bleeding was life-threatening. Missing data were not imputed.

\section{Results}

\section{Characteristics of Sites Prescribing Idarucizumab}

Of the 132 registered hospitals, 61 sites enrolled 359 patients (8 sites in the Asia-Pacific region, 42 sites in the EU, and 29 sites in North America). Just over half (52.5\%) were nonacademic institutions, and the majority were public hospitals (67.2\%) (-Table 1).

Most pharmacies (85.2\%) were centralized. In sites with decentralized pharmacies, the median number of pharmacy units per hospital was 8.0 (IQR 2.0-9.0) (-Table 1). The majority of hospitals (78.7\%) had electronic prescription and electronic medical records available, and stored idarucizumab in the primary pharmacy (67.2\%). Other storage locations include satellite pharmacies, emergency department, intensive care unit or operating room, and other specialist departments (cardiology and neurology). The median total idarucizumab units (one unit $=2 \times 2.5 \mathrm{~g}$ vials) stocked per hospital pharmacy in all storage locations was 2.0 (IQR 1.0-3.0).

Characteristics of Patients Treated with Idarucizumab Of the 359 enrolled patients, most were either in the EU (152/359 [42.3\%]) or North America (157/359 [43.7\%], of whom 140 were enrolled in the United States) (-Table 2). The majority of patients were treated in hospi- tals that were academic (208/359 [57.9\%]) and public (238/359 [66.3\%]).

Four (1.1\%) patients had received idarucizumab previously, and this information was missing for 50 (13.9\%) patients. Most patients were aged $>70$ years $(74.9 \%)$ and $85.0 \%$ had not received idarucizumab before $(98.7 \%$ if excluding the 50 patients with unknown prior use). The dose and last intake of previous anticoagulant medications (dabigatran and/or other) is shown in - Table 3. All patients had received an anticoagulant before recruitment. Dabigatran was the last anticoagulant used by most patients (97.5\%), and of these, only two (0.6\%) patients were taking dabigatran and another oral or parenteral anticoagulant (both had life-threatening or uncontrolled bleeding). Of the nine patients without dabigatran documented as their last anticoagulant medication, four had received rivaroxaban or an unknown anticoagulant, and one had received apixaban. Dabigatran dosage regimens (eight types were recorded) were known for 332 patients, with the most frequent being $150 \mathrm{mg}$ twice daily (52.4\%) and $110 \mathrm{mg}$ twice daily (35.8\%). Of those patients receiving dabigatran $110 \mathrm{mg}$ or $150 \mathrm{mg}$ twice daily, 89.9 and $60.3 \%$ were aged $>70$ years. The dose of dabigatran was not recorded for 18 (5.0\%) patients.

\section{Utilization of Idarucizumab}

Most patients (341/359 [95.0\%]) received the full dose $(2 \times$ $2.5 \mathrm{~g}$ ) of idarucizumab, with the mean (SD) time between vials being 15.3 (8.6) minutes ( - Table 4); time between two vials was missing for $123 / 341$ (36.1\%) patients. Of the 18 patients who were documented as not receiving the full dose of idarucizumab initially, 12 received one vial $(2.5 \mathrm{~g})$ and the dose was unknown for the other 6 . A second treatment with $5 \mathrm{~g}$ of idarucizumab, based on clinical signs in combination with coagulation tests, was administered to six patients $(1.7 \%)$, either in the emergency department $(n=2)$ or intensive care unit $(n=4)$. The mean (SD) time between vials for the second treatment was 14.0 (7.1) minutes, with the time between two vials missing in $2 / 6$ (33.0\%) patients. Of the six patients requiring a second full dose of idarucizumab, five given idarucizumab for initial life-threatening or uncontrolled bleeding required the second treatment for additional urgent intervention $(n=1)$ or for rebleeding/prolonged coagulation test $(n=4)$; one patient given idarucizumab initially for emergency surgery/urgent medical procedures required the second treatment for prolonged rebleeding/ prolonged coagulation test. No adverse events were reported in any patient.

Idarucizumab was primarily administered in the emergency department (209/359 [58.2\%]). Bleeding was the most frequent indication for the administration of idarucizumab (207/359 [57.7\%] patients), followed by emergency surgery/ urgent procedure (129/359 [35.9\%] patients). This pattern was consistent in most departments, except for the surgical department.

The most frequent bleeding events were GI tract (92/207 [44.4\%] of patients) and intracranial (80/207 [38.6\%]) (-Figs. 1 and 2). Most patients with GI bleeding (88/92 [95.7\%]) received the full dose $(2 \times 2.5 \mathrm{~g})$ of idarucizumab, with the mean (SD) time between vials being 15.2 
Table 1 Hospitals treating patients with idarucizumab by region

\begin{tabular}{|c|c|c|c|c|}
\hline & $\begin{array}{l}\text { Asia Pacific } \\
N=8\end{array}$ & $\begin{array}{l}\text { Europe } \\
N=24\end{array}$ & $\begin{array}{l}\text { North America } \\
N=29\end{array}$ & $\begin{array}{l}\text { Total } \\
N=61\end{array}$ \\
\hline \multicolumn{5}{|l|}{ Hospital type $1,{ }^{\mathrm{a}} n(\%)$} \\
\hline Academic & $6(75.0)$ & $15(62.5)$ & $7(24.1)$ & $28(45.9)$ \\
\hline Nonacademic & $2(25.0)$ & $9(37.5)$ & $21(72.4)$ & $32(52.5)$ \\
\hline Other & $0(0.0)$ & $0(0.0)$ & $1(3.4)$ & $1(1.6)$ \\
\hline \multicolumn{5}{|l|}{ Hospital type $2,{ }^{a} n(\%)$} \\
\hline Private & $0(0.0)$ & $1(4.2)$ & $18(62.1)$ & $19(31.1)$ \\
\hline Public & $8(100.0)$ & $23(95.8)$ & $10(34.5)$ & $41(67.2)$ \\
\hline Other & $0(0.0)$ & $0(0.0)$ & $1(3.4)$ & $1(1.6)$ \\
\hline \multicolumn{5}{|l|}{ Type of pharmacy, $n(\%)$} \\
\hline Central pharmacy & $7(87.5)$ & $23(95.8)$ & $22(75.9)$ & $52(85.2)$ \\
\hline Decentralized pharmacy & $1(12.5)$ & $1(4.2)$ & $7(24.1)$ & $9(14.8)$ \\
\hline \multicolumn{5}{|l|}{$\begin{array}{l}\text { Availability of electronic prescription records at } \\
\text { the pharmacy, } n(\%)\end{array}$} \\
\hline Yes & $4(50.0)$ & $16(66.7)$ & $28(96.6)$ & $48(78.7)$ \\
\hline No & $4(50.0)$ & $8(33.3)$ & $1(3.4)$ & $13(21.3)$ \\
\hline \multicolumn{5}{|l|}{$\begin{array}{l}\text { Availability of electronic medical records at the } \\
\text { pharmacy, } n(\%)\end{array}$} \\
\hline Yes & $5(62.5)$ & $16(66.7)$ & $27(93.1)$ & $48(78.7)$ \\
\hline No & $3(37.5)$ & $8(33.3)$ & $2(6.9)$ & $13(21.3)$ \\
\hline Number of pharmacy units per hospital, ${ }^{\mathrm{b}} n(\%)$ & 1 & 1 & 7 & 9 \\
\hline Median (IQR) & $9.0(9.0-9.0)$ & $3.0(3.0-3.0)$ & $8.0(1.0-10.0)$ & $8.0(2.0-9.0)$ \\
\hline $\begin{array}{l}\text { Total number of idarucizumab units }(2 \times 2.5 \mathrm{~g}) \\
\text { stocked per hospital pharmacy in all storage } \\
\text { locations, }{ }^{\mathrm{C}} n(\%)\end{array}$ & 8 & 24 & 28 & 60 \\
\hline Median (IQR) & $2.0(1.0-3.0)$ & $2.0(2.0-3.5)$ & $2.0(1.0-2.0)$ & $2.0(1.0-3.0)$ \\
\hline \multicolumn{5}{|l|}{ Storage location of idarucizumab stocks, ${ }^{\mathrm{c}, \mathrm{d}} n(\%)$} \\
\hline Primary pharmacy & $5(62.5)$ & $11(45.8)$ & $25(86.2)$ & $41(67.2)$ \\
\hline Satellite pharmacy & $0(0.0)$ & $0(0.0)$ & $0(0.0)$ & $0(0.0)$ \\
\hline Emergency room & $2(25.0)$ & $9(37.5)$ & $7(24.1)$ & $18(29.5)$ \\
\hline Other & $3(37.5)$ & $12(50.0)$ & $0(0.0)$ & $15(24.6)$ \\
\hline
\end{tabular}

Abbreviation: IQR, interquartile range.

${ }^{a}$ Type 1: academic sector type; Type 2: practice hospital type.

${ }^{b}$ Only available when type of pharmacy is decentralized pharmacy.

'Data for 1 hospital pharmacy missing for North America.

${ }^{\mathrm{d}}$ Multiple answers possible.

(9.8) minutes. Similarly, the majority of patients with intracranial bleeding (76/80 [95.0\%]) received the full dose of idarucizumab, with the mean (SD) time between vials being 16.3 (7.1) minutes. Of the $194 / 207$ (93.7\%) patients who received the full dose $(2 \times 2.5 \mathrm{~g})$ of idarucizumab for a bleeding event, the time between two vials was not available for $68 / 194$ (35.1\%) patients. For those patients who received the full dose $(2 \times 2.5 \mathrm{~g})$ of idarucizumab for GI or intracranial bleeding events, the time between two vials was not available for $28 / 88$ (31.8\%) and 25/76 (32.9\%) patients, respectively. Four patients $(1.1 \%)$ were reported to have prematurely discontinued idarucizumab, with none due to adverse events.
Of the 141 (39.3\%) patients who were administered idarucizumab for emergency or for scheduled or planned surgery/procedure (-Figs. 2 and 3), GI and/or abdominal surgery or procedures were most frequently performed (in 36 [25.5\%] of patients), followed by orthopedic procedures (in 31 [22.0\%] patients), thoracic surgery including cardiac surgery (23 [16.3\%] patients), and vascular operations (in 20 [14.2\%] patients). Of the 23 patients who received idarucizumab for thoracic surgery including cardiac surgery, 6 patients underwent cardiac catheterization, 3 patients had a cardiac pacemaker insertion or removal, 1 patient had a central venous catheterization, and 5 patients had a pericardial excision and pericardial drainage. No intraprocedural 
Table 2 Characteristics of patients treated with idarucizumab by region

\begin{tabular}{|c|c|c|c|c|}
\hline & $\begin{array}{l}\text { Asia Pacific } \\
N=50\end{array}$ & $\begin{array}{l}\text { Europe } \\
N=152\end{array}$ & $\begin{array}{l}\text { North America } \\
N=157\end{array}$ & $\begin{array}{l}\text { Total } \\
N=359\end{array}$ \\
\hline \multicolumn{5}{|c|}{ Age group (y), $n(\%)$} \\
\hline $18-50$ & $2(4.0)$ & $4(2.6)$ & $5(3.2)$ & $11(3.1)$ \\
\hline $51-70$ & $11(22.0)$ & $28(18.4)$ & $40(25.5)$ & $79(22.0)$ \\
\hline$>70$ & $37(74.0)$ & $120(78.9)$ & $112(71.3)$ & $269(74.9)$ \\
\hline \multicolumn{5}{|c|}{ Prior administration of idarucizumab, $n(\%)$} \\
\hline Yes & $0(0.0)$ & $1(0.7)$ & $3(1.9)$ & $4(1.1)$ \\
\hline No & $48(96.0)$ & $129(84.9)$ & $128(81.5)$ & $305(85.0)$ \\
\hline Unknown & $2(4.0)$ & $22(14.5)$ & $26(16.6)$ & $50(13.9)$ \\
\hline \multicolumn{5}{|c|}{ Hospital type $1,{ }^{\mathrm{a}} \mathrm{n}(\%)$} \\
\hline Academic & $41(82.0)$ & $108(71.1)$ & $59(37.6)$ & $208(57.9)$ \\
\hline Nonacademic & $9(18.0)$ & $44(28.9)$ & $93(59.2)$ & $146(40.7)$ \\
\hline Other & $0(0.0)$ & $0(0.0)$ & $5(3.2)$ & $5(1.4)$ \\
\hline \multicolumn{5}{|c|}{ Hospital type $2,{ }^{a} n(\%)$} \\
\hline Private & $0(0.0)$ & $10(6.6)$ & $87(55.4)$ & $97(27.0)$ \\
\hline Public & $50(100.0)$ & $142(93.4)$ & $46(29.3)$ & $238(66.3)$ \\
\hline Other & $0(0.0)$ & $0(0.0)$ & $24(15.3)$ & $24(6.7)$ \\
\hline
\end{tabular}

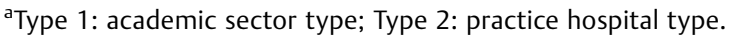

Table 3 Last anticoagulant medication taken prior to recruitment, according to the reason for idarucizumab administration

\begin{tabular}{|l|l|l|l|l|l|}
\hline & $\begin{array}{l}\text { Life-threatening or } \\
\text { uncontrolled } \\
\text { bleeding } \\
\mathbf{N}=\mathbf{2 0 7}\end{array}$ & $\begin{array}{l}\text { Emergency surgery } \\
\text { or other urgent } \\
\text { medical procedure } \\
N=129\end{array}$ & $\begin{array}{l}\text { Scheduled or } \\
\text { planned surgery/ } \\
\text { procedure } \\
N=12\end{array}$ & $\begin{array}{l}\text { Other } \\
N=11\end{array}$ & $\begin{array}{l}\text { Total } \\
N=359\end{array}$ \\
\hline Anticoagulant medication, $n(\%)$ & & & $12(100.0)$ & $11(100.0)$ & $350(97.5)^{\mathrm{a}}$ \\
\hline Dabigatran any dose & $203(98.1)$ & $124(96.1)$ & $0(0.0)$ & $0(0.0)$ & $4(1.1)$ \\
\hline Rivaroxaban any dose & $3(1.4)$ & $1(0.8)$ & $0(0.0)$ & $0(0.0)$ & $1(0.3)$ \\
\hline Apixaban any dose & $0(0.0)$ & $1(0.8)$ & $0(0.0)$ & $0(0.0)$ & $0(0.0)$ \\
\hline Edoxaban any dose & $0(0.0)$ & $0(0.0)$ & $0(0.0)$ & $0(0.0)$ & $0(0.0)$ \\
\hline Vitamin K antagonist & $0(0.0)$ & $0(0.0)$ & $0(0.0)$ & $0(0.0)$ & $2(0.6)$ \\
\hline Other anticoagulant & $2(1.0)$ & $0(0.0)$ & $0(0.0)$ & $0(0.0)$ & $6(1.7)^{\mathrm{b}}$ \\
\hline Unknown & $2(1.0)$ & $4(3.1)$ & & & \\
\hline
\end{tabular}

ancludes two patients who received $\geq 1$ dose dabigatran plus other anticoagulant.

Includes two patients who were receiving another known anticoagulant medication.

bleeds were reported. The study also included patients who required rapid reversal of the anticoagulant effect of dabigatran prior to thrombolysis $(n=12)$ and thrombectomy $(n=$ 2 ). On average, data were missing for $6.4 \%$ of patients with regard to the type of surgery/procedure; 8/129 (6.2\%) patients underwent emergency surgery or other urgent medical procedures, and $1 / 12(8.3 \%)$ patients who underwent scheduled or planned surgery/procedures.

\section{Discussion}

The RE-VECTO postapproval surveillance study has shown that sites prescribing idarucizumab were mainly nonaca- demic institutions and public hospitals, with approximately two doses of idarucizumab stored onsite. Most of the patients were European or North American. More than half of the registered hospitals either registered proactively prior to identification of a patient treated with idarucizumab or had historical cases of patients treated with idarucizumab but did not enter patients into the registry. Of those sites that entered patient data, as expected, dabigatran was the anticoagulant used by most patients. Nearly all patients received the full dose $(2 \times 2.5 \mathrm{~g})$ of idarucizumab, with only one full dose required in almost all patients. There was minimal offlabel dosing (e.g., use of $2.5 \mathrm{~g}$ in 12 patients), and administration of idarucizumab to 7 patients using FXa inhibitors 
Table 4 Idarucizumab utilization according to the reason for idarucizumab administration

\begin{tabular}{|c|c|c|c|c|c|}
\hline & $\begin{array}{l}\text { Life-threatening } \\
\text { or uncontrolled } \\
\text { bleeding } \\
N=207\end{array}$ & $\begin{array}{l}\text { Emergency surgery } \\
\text { or other urgent } \\
\text { medical procedure } \\
N=129\end{array}$ & $\begin{array}{l}\text { Scheduled or } \\
\text { planned surgery/ } \\
\text { procedure } \\
N=12\end{array}$ & $\begin{array}{l}\text { Other } \\
N=11\end{array}$ & $\begin{array}{l}\text { Total } \\
N=359\end{array}$ \\
\hline \multicolumn{6}{|l|}{ Idarucizumab total dose, $n(\%)$} \\
\hline $2.5 \mathrm{~g}$ (1 vial) & $7(3.4)$ & $5(3.9)$ & $0(0.0)$ & $0(0.0)$ & $12(3.3)$ \\
\hline $5 \mathrm{~g}$ (2 vials) & $195(94.2)$ & $123(95.3)$ & $12(100.0)$ & $11(100.0)$ & $341(95.0)$ \\
\hline Other & $5(2.4)$ & $1(0.8)$ & $0(0.0)$ & $0(0.0)$ & $6(1.7)$ \\
\hline \multicolumn{6}{|l|}{ Time between 2 vials $(\min )^{\mathrm{c}, \mathrm{d}}$} \\
\hline$N$ & 127 & 83 & 7 & 1 & 218 \\
\hline Mean (SD) & $15.80(8.72)$ & $14.20(8.59)$ & $16.14(5.70)$ & $25.00(-)$ & $15.25(8.60)$ \\
\hline \multicolumn{6}{|l|}{$\begin{array}{l}\text { Second round of } \\
\text { idarucizumab } 5 \mathrm{~g}, n(\%)\end{array}$} \\
\hline No & $198(95.7)$ & $125(96.9)$ & $12(100.0)$ & $11(100.0)$ & $346(96.4)$ \\
\hline Yes & $5(2.4)$ & $1(0.8)$ & $0(0.0)$ & $0(0.0)$ & $6(1.7)$ \\
\hline Unknown & $4(1.9)$ & $3(2.3)$ & $0(0.0)$ & $0(0.0)$ & $7(1.9)$ \\
\hline \multicolumn{6}{|l|}{ Reason for second round, ${ }^{\mathrm{e}} \mathrm{n}(\%)$} \\
\hline Additional urgent intervention & $1(20.0)$ & $0(0.0 \%)$ & $0(0.0)$ & $0(0.0)$ & 1 (16.7) \\
\hline $\begin{array}{l}\text { Rebleeding/coagulation } \\
\text { test prolongation }\end{array}$ & $4(80.0)$ & $1(100.0)$ & $0(0.0)$ & $0(0.0)$ & $5(83.3)$ \\
\hline \multicolumn{6}{|l|}{$\begin{array}{l}\text { Time between } 2 \text { vials for } \\
\text { second round }(\min )^{c, e, f}\end{array}$} \\
\hline$N$ & 4 & 0 & 0 & 0 & 4 \\
\hline Mean (SD) & $14.00(7.12)$ & - & - & - & $14.00(7.12)$ \\
\hline
\end{tabular}

Abbreviations: ICU, intensive care unit; SD, standard deviation.

a Life-threatening or uncontrolled bleeding requiring urgent medical intervention.

${ }^{b}$ Emergency surgery or other urgent medical procedure necessitating rapid reversal of dabigatran prior to surgery or procedure (emergency defined as within the next 8 hours).

${ }^{\mathrm{C}}$ Calculated only for those patients administered total dose of $5 \mathrm{~g}$ ( 2 vials), and defined as the end time of second vial minus the start time of the first vial. If the start or end time of dosing was unknown, the estimated time of total infusion was used; if this estimate was not known, then time was set to missing. ${ }^{\mathrm{d}}$ Missing data for 68 patients in the emergency setting, 40 in the operating setting, 5 in the intensive care setting, and 10 in the other setting.

${ }^{\mathrm{e}}$ Among patients who had second round of dosing with $5 \mathrm{~g}$ of idarucizumab.

${ }^{\mathrm{f}}$ Missing data for 1 patient in the emergency and ICU settings.

(without dabigatran) was reported. As expected, idarucizumab was most frequently given in the emergency department, and bleeding (the most common locations being GI tract and intracranial) was the most frequent reason for administering idarucizumab.

The findings from RE-VECTO describing idarucizumab uptake, dabigatran prescribing patterns, and patient characteristics in the real-world setting add to the idarucizumab clinical trial data and few case collections available to date. ${ }^{10,13-20}$ While the patients in RE-VECTO were less well characterized due to the limitations of data collection, outcomes were largely consistent with those observed in the clinical trial setting with regard to indications, rates of bleeding, and emergent surgery events. In addition, REVECTO demonstrates that the real-world usage of idarucizumab was mostly as recommended in the label. Moreover, the reversal of dabigatran in RE-VECTO rarely required a second round of idarucizumab dosing ( $<2 \%$ of patients), supporting the findings from the RE-VERSE-AD study in which a second round of dosing was required in $1.6 \%$ of patients. ${ }^{10}$ In addition, the reversal of dabigatran in the real-world setting involved a mainly elderly population treated with several different dabigatran dosage regimens. In RE-VERSE-AD, the median age was 78 (range, 2196) years, and $>97 \%$ of patients received one of three approved dosage regimens of dabigatran (150/110/75 mg twice daily).

Aside from idarucizumab, one other reversal agent, andexanet alfa, is available commercially in the United States for the reversal of rivaroxaban- and apixaban-related bleeding only, following positive results from clinical trials. ${ }^{21,22}$ Another potential FXa inhibitor reversal agent, ciraparantag, has yet to begin phase II or III evaluation in patient settings; phase II data in healthy volunteers administered rivaroxaban (NCT03172910) or apixaban (NCT03288454) are expected in 2019.

The RE-VECTO surveillance program was designed to collect data on drug use in a simple and effective way, 


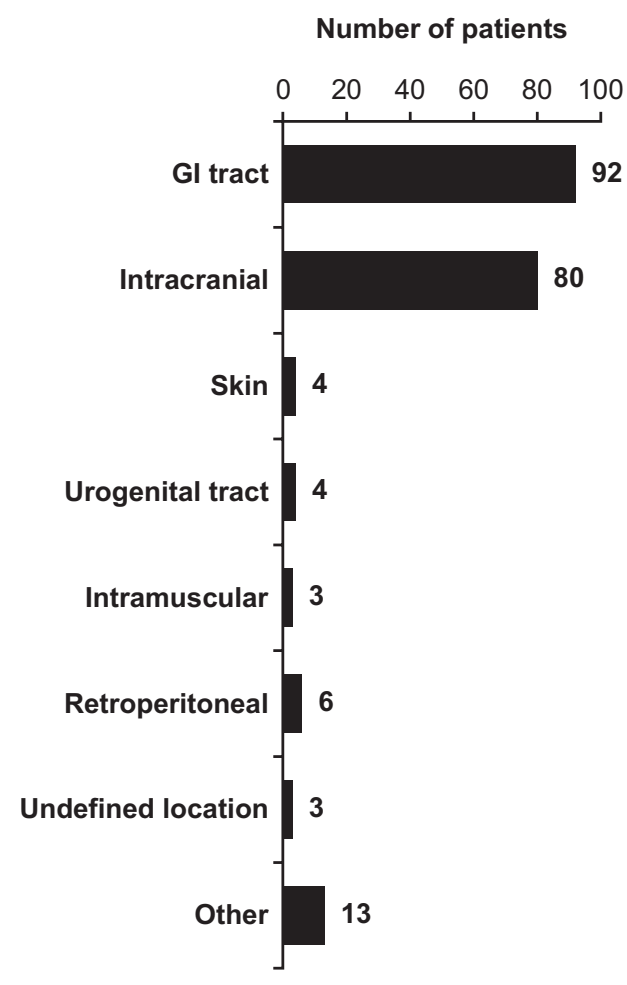

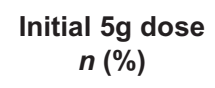

$13(100.0)$
Mean (SD) time between vials ${ }^{b, c}$ (minutes)

$15.2(9.8)$

$16.3(7.1)$

$35.0(-)$

NE

$11.0(-)$

$22.5(3.5)$

$17.3(8.3)$

$0(0.0)$

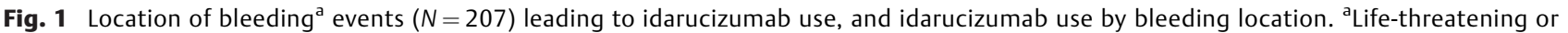
uncontrolled bleeding requiring medical intervention. ${ }^{\mathrm{b}} \mathrm{Calculated}$ only for those patients administered total dose of $5 \mathrm{~g}$ ( 2 vials), and defined as the end time of second vial minus the start time of the first vial. If the start or end time of dosing was unknown, the estimated time of total infusion was used; if this estimate was not known, then time was set to missing. 'Missing data for 28 patients with gastrointestinal tract bleeding, 25 with intracranial bleeding, 3 with skin bleeding, 3 with urogenital tract bleeding, 1 with intramuscular bleeding, 2 with retroperitoneal bleeding, and 6 with other bleeding locations. GI, gastrointestinal; NE, not evaluable; SD, standard deviation.

\section{RE-VECTO program}

- Cross-sectional surveillance program of idarucizumab use (August 2016 to June 2018)

- Hospital pharmacies (61 sites) in North America, the European Union, Asia Pacific

\section{Location of life-threatening bleeding events $(N=207)$}

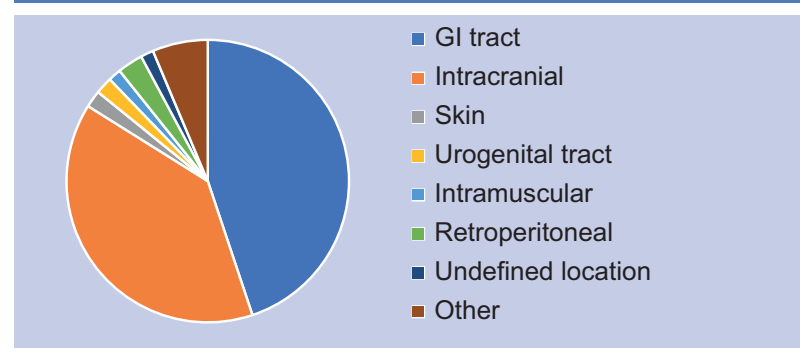

\section{Idarucizumab}

- Humanized mouse monoclonal antibody fragment that binds dabigatran with high affinity

- Used in patients with life-threatening bleeds or need for emergency surgery

\section{Type of surgery or procedure by indication for idarucizumab use $(N=141)$}

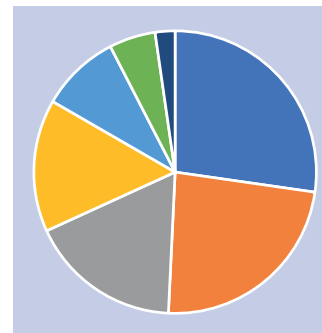

- Gl/abdominal surgery/procedures

- Orthopedic procedures

$\square$ Thoracic (including cardiac) surgery

- Vascular surgery

- Cerebrovascular/nervous

system procedures

$\square$ Genitourinary surgery

- Neck surgery

\section{Insights from RE-VECTO}

- The first analysis of idarucizumab use in a real-world setting

- $5 \mathrm{~g}$ idarucizumab was used appropriately in $>98 \%$ of dabigatran-treated patients

- Idarucizumab use was consistent with data collected from clinical trial settings

Fig. 2 RE-VECTO surveillance program. GI, gastrointestinal. 


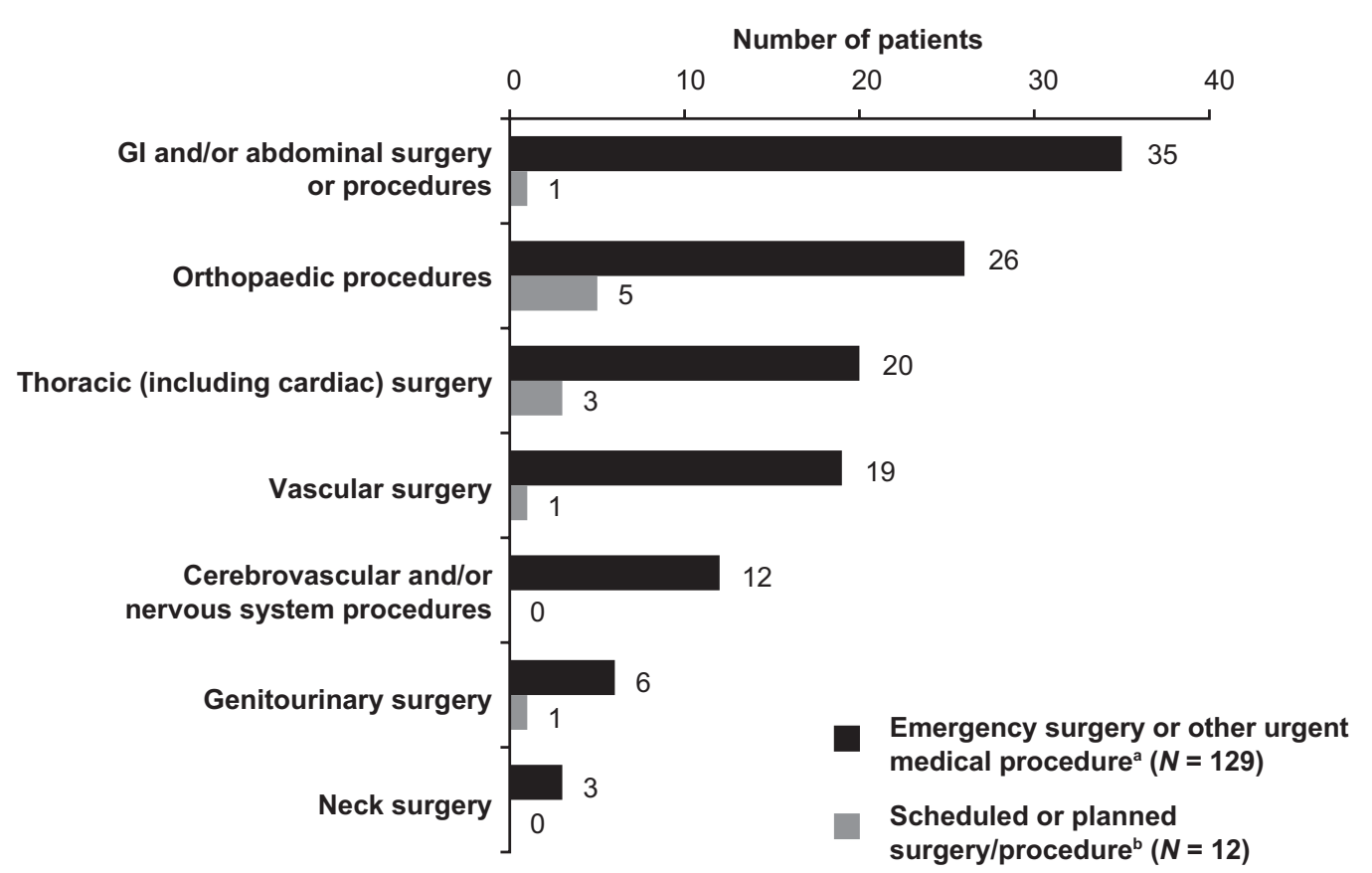

Fig. 3 Type of surgery or procedure by indication for idarucizumab use. ${ }^{a}$ Missing data for 8 patients undergoing emergency surgery or other urgent medical procedures. ${ }^{\mathrm{b}}$ Missing data for 1 patient undergoing scheduled or planned surgery/procedures.

although the voluntary registration design and/or resource limitations may have reduced participation and resulted in some incomplete data sets. Some recruited sites known to be prescribing idarucizumab did not enter patient data in the registry during the specified time period for data collection, and were not actively surveyed. Data listing reviews conducted prior to database lock did not involve an independent data review committee, and onsite source data verification was not conducted. Administration of idarucizumab is rare, and without patient data being entered into the registry, we are unable to ascertain whether these sites were restocking idarucizumab, supplying satellite locations within the hospital, replacing expired idarucizumab, or administering idarucizumab to patients. Nevertheless, drug surveillance programs are one source of real-world data ${ }^{23}$ that are particularly useful for identifying improper use. By identifying potential risks, action can be taken to help minimize the risk of adverse drug reactions resulting from medication errors. This study assessed idarucizumab utilization in a predefined sample of prescriptions in the clinical practice setting, based on medical and pharmacy record review. This approach was in line with postmarketing surveillance requested by the European Medicines Agency.

\section{Conclusion}

Real-world information from the RE-VECTO surveillance program adds to the data obtained from idarucizumab clinical trials and provides valuable insights into the current strategies employed to reverse the anticoagulation effects of dabigatran in emergency situations. Usage patterns of idarucizumab were aligned with idarucizumab prescribing information, with minimal off-label use (see - Fig. 2).

\section{What is known about this topic?}

- Limited data are available that describe idarucizumab utilization in routine clinical practice.

- Postmarketing observational studies can provide insight into the use of medications in the real world where there is a broad patient population with various comorbidities and concomitant therapies.

\section{What does this paper add?}

- It provides the first insight into how a NOAC reversal agent is used in the real-world setting, examining where idarucizumab is prescribed (across regions and within hospitals), the patients who receive idarucizumab, and why they received it.

- The RE-VECTO study confirmed that $5 \mathrm{~g}$ of idarucizumab was used appropriately in $>98 \%$ of dabigatrantreated patients with life-threatening bleeding or in need of emergency surgery.

- Idarucizumab use was generally consistent with the data collected in the clinical trial setting with minimal off-label prescribing.

Authors' Contributions

All authors were involved with designing the surveillance program, provided critical review of the article, and approved the final version for publication.

Funding

The RE-VECTO surveillance program was funded by Boehringer Ingelheim Pharma GmbH \& Co. KG. 


\section{Conflict of Interest}

J.F. has consulted for Boehringer Ingelheim, Genentech, and Portola. D.M., F.G., P.A.R., and I.T. are employees of Boehringer Ingelheim. L.R.F. was an employee of Boehringer Ingelheim at the time of manuscript writing and is now employed by Sanofi-Aventis. D.A.L. has received investigator-initiated educational grants from BristolMyers Squibb (BMS) and Boehringer Ingelheim; has been a speaker for Boehringer Ingelheim, Bayer, and BMS/Pfizer; and has consulted for BMS, Bayer, Boehringer Ingelheim, and Daiichi-Sankyo. P.K. served as a speaker/ has consulted for Boehringer Ingelheim, Bayer, BMS/ Pfizer, and Portola. F.V.W. served as a speaker/has consulted for Boehringer Ingelheim, Bayer, BMS/Pfizer, Takeda, and Leo Pharma. K.B. has served on advisory boards, received investigator-initiated research grants, and served as a speaker for Boehringer Ingelheim, Bayer, and BMS/Pfizer.

\section{Acknowledgment}

Medical writing assistance, supported financially by Boehringer Ingelheim Pharma GmbH \& Co. KG, was provided by Parexel during the preparation of this article.

\section{References}

1 Greinacher A, Thiele T, Selleng K. Reversal of anticoagulants: an overview of current developments. Thromb Haemost 2015;113 (05):931-942

2 Das A, Liu D. Novel antidotes for target specific oral anticoagulants. Exp Hematol Oncol 2015;4:25

3 Kirchhof P, Benussi S, Kotecha D, et al; ESC Scientific Document Group. 2016 ESC Guidelines for the management of atrial fibrillation developed in collaboration with EACTS. Eur Heart J 2016;37 (38):2893-2962

4 Macle L, Cairns J, Leblanc K, et al; CCS Atrial Fibrillation Guidelines Committee. 2016 Focused update of the Canadian Cardiovascular Society guidelines for the management of atrial fibrillation. Can J Cardiol 2016;32(10):1170-1185

5 European Medicines Agency. 2015. Idarucizumab summary of product characteristics. Available at: https://www.ema.europa. eu/documents/product-information/praxbind-epar-productinformation_en.pdf. Accessed October 10, 2018

6 US Food and Drug Administration. 2015. Idarucizumab prescribing information. Available at: https://www.accessdata.fda.gov/ drugsatfda_docs/label/2015/761025lbl.pdf. Accessed October 10, 2018

7 US Food and Drug Administration. 2018. Andexanet alfa prescribing information. Available at: https://www.fda.gov/downloads/ BiologicsBloodVaccines/CellularGeneTherapyProducts/Approved Products/UCM606687.pdf. Accessed October 10, 2018
8 Eikelboom JW, Quinlan DJ, van Ryn J, Weitz JI. Idarucizumab: the antidote for reversal of dabigatran. Circulation 2015;132(25): 2412-2422

9 Schiele F, van Ryn J, Canada K, et al. A specific antidote for dabigatran: functional and structural characterization. Blood 2013;121(18):3554-3562

10 Pollack CV Jr, Reilly PA, van Ryn J, et al. Idarucizumab for dabigatran reversal - full cohort analysis. N Engl J Med 2017; 377(05):431-441

11 European Medicines Agency. Dabigatran etexilate. Summary of Product Characteristics. Available at: https://www.ema.europa. eu/documents/product-information/pradaxa-epar-productinformation_en.pdf. Accessed October 10, 2018

12 US Food and Drug Administration. Dabigatran etexilate prescribing information. Available at: https://www.accessdata.fda.gov/drugsatfda_docs/label/2018/022512s035lbl.pdf. Accessed October 10, 2018

13 Pollack CV Jr, Reilly PA, Eikelboom J, et al. Idarucizumab for dabigatran reversal. N Engl J Med 2015;373(06):511-520

14 Glund S, Stangier J, Schmohl M, et al. Safety, tolerability, and efficacy of idarucizumab for the reversal of the anticoagulant effect of dabigatran in healthy male volunteers: a randomised, placebo-controlled, double-blind phase 1 trial. Lancet 2015;386(9994):680-690

15 van Ryn J, Yasaka M, Ikushima I, et al. Idarucizumab, a specific reversal agent for dabigatran: immediate, complete and sustained reversal of dabigatran-induced anticoagulation in Japanese healthy male volunteers. Blood 2016;128(Suppl 22):2627

16 Glund S, Stangier J, van Ryn J, et al. Effect of age and renal function on idarucizumab pharmacokinetics and idarucizumab-mediated reversal of dabigatran anticoagulant activity in a randomized, double-blind, crossover phase Ib study. Clin Pharmacokinet 2017; 56(01):41-54

17 Glund S, Stangier J, Schmohl M, et al. Idarucizumab, a specific antidote for dabigatran: immediate, complete and sustained reversal of dabigatran induced anticoagulation in elderly and renally impaired subjects. Blood 2014;124(Suppl 21):344

18 Fang CW, Tsai YT, Chou PC, et al. Intravenous thrombolysis in acute ischemic stroke after idarucizumab reversal of dabigatran effect: analysis of the cases from Taiwan. J Stroke Cerebrovasc Dis 2019;28(03):815-820

19 Kermer P, Eschenfelder CC, Diener HC, et al. Antagonizing dabigatran by idarucizumab in cases of ischemic stroke or intracranial hemorrhage in Germany - a national case collection. Int J Stroke 2017;12(04):383-391

20 van der Wall SJ, van Rein N, van den Bemt B, et al. Performance of idarucizumab as antidote of dabigatran in daily clinical practice. Europace 2019;21(03):414-420

21 Connolly SJ, Milling TJ Jr, Eikelboom JW, et al; ANNEXA-4 Investigators. Andexanet alfa for acute major bleeding associated with factor Xa inhibitors. N Engl J Med 2016;375(12):1131-1141

22 Siegal DM, Curnutte JT, Connolly SJ, et al. Andexanet alfa for the reversal of factor Xa inhibitor activity. N Engl J Med 2015;373(25): 2413-2424

23 Martin K, Bégaud B, Latry P, Miremont-Salamé G, Fourrier A, Moore N. Differences between clinical trials and postmarketing use. Br J Clin Pharmacol 2004;57(01):86-92 